\title{
Clinical Presentation of Left Atrial Myxoma in Relation to Anatomic and Pathologic Type
}

\author{
SM Mahbubur Rahman'1, M Golam Kibria ${ }^{1}$, AM Asif Rahim ${ }^{1}$, Nazmul Hosain ${ }^{2}$, M Abul Quashem ${ }^{1}$ \\ ${ }^{1}$ Department of Cardiac Surgery, NICVD, ${ }^{2}$ Department of Cardiac Surgery, Chittagong Medical \\ College, Chittagong
}

Key Words :

Myxoma,

Atrium.

\begin{abstract}
:
Background: Atrial myxoma is the most common benign cardiac neoplasm. Most of the case series have focused on the variable clinical presentation of myxoma rather than its gross and microscopic features. The objective of our study was to evaluate prevalence of different morphologic types of myxoma and to correlate with their clinical presentations.
\end{abstract}

Methods: 68 patients were included in the study. The study population was divided into two groups-Group-A (n-18) patients having soft (papillary) tumor in the left atrium, Group B ( $n=50)$ patients having solid tumor in the left atrium.

Results: $88.3 \%$ patients suffered illness more than 12 months. $92 \%$ of the solid myxomas were located in the septal wall compared to $55.6 \%$ of the papillary myxomas $(p=0.031)$, while one-third $(33.3 \%)$ the papillary tumors were found in the left atrial free wall compared to only $4 \%$ of the solid myxomas $(p=0.048)$. Fever, congestive heart failure and dyspnoea were significantly predominant in patients with solid myxomas $(72 \%$ vs. $44.4 \%, p=0.036$; $92 \%$ vs. $22.2 \%, p<0.001$ and $88 \%$ vs. $55.6 \%$, $p=0.010$ respectively). Atrial fibrillation and neurologic manifestations were more frequently encountered in the papillary myxoma group. No statistically significant difference was found between the groups $(p>0.05)$ by postoperative complication during in hospital follow up but one mortality in each group.

Conclusion: Our findings lend support to the view that different gross left atrial Myxoma tumor types and tumor location predict presentation.

(Cardiovasc. j. 2015; 8(1): 19-22)

\section{Introduction:}

Atrial myxoma is the most common type of benign cardiac neoplasm. Origin of myxoma has been ascribed with some debate, to a multi potential mesenchymal cell. Although benign, prompt operative removal after clinical recognition is prudent since early series noted an $8 \%$ incidence of sudden death in patients awaiting surgery. The first surgical excision of a myxoma was reported by Bahnson and Newman in 1952. ${ }^{1}$ In 1954 Crafoord $^{2}$ reported excision of myxoma using CPB.

Two anatomic types have been observed-1) solid and ovoid and 2) Soft gelatinous and papillary. Very few studies have been conducted to understand whether differences in gross or microscopic appearance and location correlated with symptoms, specifically congestive heart failure ( $\mathrm{CHF})$, neurologic symptoms, and embolic events. ${ }^{2}$

Myxomas account for $40-50 \%$ of primary cardiac tumors. Approximately $90 \%$ are solitary and pedunculated, and $75-85 \%$ occurs in the left atrial cavity. Next common site is in the right atrium. Most cases are sporadic. Approximately 10\% are famillial and are transmitted in an autosomal dominant mode. Multiple tumors occur in approximately $50 \%$ of familial cases. Myxoma in the ventricle also occur more frequently in familial cases ( $13 \%$ vs $2 \%)^{2,3}$

Left atrial myxoma may present with myriads of clinical symptoms. CHF is the most common clinical presentation with neurologic and systemic embolic events being less frequent. Most series have focused on the variable clinical presentation of patients rather than gross and microscopic features of the tumors. Heath (1968) first noted two distinct gross anatomic types of atrial myxoma, a solid (firm and smooth) and papillary gelatinous (soft and friable). The Mayo clinic series also classified myxomas into two gross anatomic types and a report by Shimono et al. found that clinical

Address of Correspondence: Dr. SM Mahbubur Rahman, Department of Cardiac Surgery, National Institute of cardiovascular Diseases, Dhaka, Bangladesh. E-mail: mahbub94968@yahoo.com 
presentation correlated with gross tumor appearance. ${ }^{2,4}$

The most recent significant milestone was the introduction by Shattenberg in 1968 of echocardiography as a reliable imaging modality for cardiac tumors. Whether differences in gross and morphologic appearance and location of the tumor correlate with symptoms, specially congestive heart failure ( $\mathrm{CHF})$, neurologic symptoms and embolic events is not established yet. Approach to a patient with myxoma, "elective or emergency" is still in debate. Which group of patient should be immediately operated and which group can be deferred are extremely important for the cardiac surgeons as well as cardiologist. ${ }^{2}$

In early 1990s some works have been done on LA myxoma in Bangladesh. Whether any significant correlation exists between symptoms and gross \& microscopic appearance and tumor location has not been done so far.

Size of tumor varies ranging from $(1.5 \mathrm{~cm} \mathrm{X} 2.0$ $\mathrm{cm})$ to $(9.0 \mathrm{~cm} \mathrm{X} 7.0 \mathrm{~cm}) .5$ Most of the benign cardiac tumors are located in the left atrium. Most commonly it is attached to the limbal tissue around the Fossa ovalis. Familial myxomas are more common in females of younger age group but sporadic tumors are can occur at any age though more common in 3 rd to $6^{\text {th }}$ decades of life. ${ }^{4}$

It has become increasingly apparent that it is necessary to alert the surgeons and physicians to the clinical manifestation of cardiac tumors. There is a resurgence of interest in this aspect of heart disease and rightfully so because cardiac tumors are more prevalent than generally realized and prompt recognition and surgical removal of some of the primary tumors can be life saving. 8 to $10 \%$ patients with left atrial myxoma died before they got admitted in to the hospital. Majority of myxomas can be diagnosed early with the help of echocardiography if high index of suspicion focused on clinical presentation. Learning how to categorize myxoma patients might reduce morbidity and mortality. So we carried out a study on left atrial myxoma, its various types, clinical presentation and histological type. ${ }^{6}$

\section{Methods:}

This study was conducted at Cardiac surgery department of National Institute of Cardiovascular Diseases (NICVD) during the period of July-2006 to June-2008. All consecutive patients admitted in NICVD (cardiac surgery department) diagnosed with left atrial myxoma for operation were taken as study population.

Total number of patients was sixty eight (68) and divided in two groups. Group A $(\mathrm{n}=18)$ included patients having soft (papillary) tumor in the left atrium. And Group B ( $\mathrm{n}=50)$ included patients having solid tumor in the left atrium. Informed written consents of the patients were taken. The study protocol was approved by institutional review board. Data were collected in preformed data collection form. Patients with associated valvular disease, congenital heart disease, coronary artery disease were excluded from the study. Patient's symptoms, clinical findings and echocardiographic findings were preoperative variables while tumor size ,location of tumor, gross appearance were peroperative and histological findings of excised tumor were postoperative variables respectively. Statistical analysis done by SPSS programme and $\mathrm{p}$ value $<0.05$ were considered as statistically significant.

\section{Results:}

Of the 68 subjects having atrial myxoma, 50 had solid myxoma and 18 had papillary myxoma. Among the 68 study population majority belonged to $40-50$ years age group $(35.3 \%)$ where as above 50 yrs were $23.5 \%, 30-40$ years were $20.6 \%,<20$ years $11.8 \%$ and $20-30$ years $8.8 \%$ respectively. Mean age were $38.4 \pm 12$.4years. Out of 68 patients, $38(56 \%)$ were male and $30(44 \%)$ were female giving a male to female ratio of roughly -5:4. Majority $(88.3 \%)$ of the patients at presentation had been suffering from the disease for 12 months or more, $8.8 \%$ for $6-12$ months and $2.9 \%$ less than 6 months. The mean duration of illness was $20.7 \pm$ 10.3 months and the lowest and highest durations of illness were 2.4 and 48 months respectively.

Table-I

Association between anatomical location and types of tumour $(n=68)$.

\begin{tabular}{lccc}
\hline $\begin{array}{l}\text { Anatomical } \\
\text { location }\end{array}$ & \begin{tabular}{c} 
Atrial \\
\cline { 2 - 3 }$(\mathrm{n}=50)$
\end{tabular} & $\begin{array}{c}\text { myxoma } \\
(\mathrm{n}=18)\end{array}$ & P value \\
\hline Septum & $46(92)$ & $10(55.6)$ & 0.031 \\
Anterior left atrium & $2(4)$ & $2(11.1)$ & 0.465 \\
Lateral left atrium & $2(4)$ & $6(33.3)$ & 0.048 \\
$\begin{array}{l}\text { Superior left atrium } \\
\text { Left inferior }\end{array}$ & $0(0.0)$ & $0(0.0)$ & $\ldots \ldots \ldots .$. \\
pulmonary vein & $0(0.0)$ & $2(11.1)$ & 0.265 \\
\hline
\end{tabular}

*Figures in the parentheses denote corresponding percentage. 


\section{Table-II}

Comparison of general and cardiovascular presentations $(n=68)$.

\begin{tabular}{lccc}
\hline $\begin{array}{l}\text { Clinical } \\
\text { presentation }\end{array}$ & \begin{tabular}{c} 
Atrial Myxoma \\
\cline { 2 - 3 }
\end{tabular} & $\begin{array}{c}\text { Solid } \\
(\mathrm{n}=50)\end{array}$ & $\begin{array}{c}\text { Papillary } \\
(\mathrm{n}=18)\end{array}$ \\
\hline Fever & $36(72.0)$ & $8(44.4)$ & 0.036 \\
Chest pain & $28(56.0)$ & $8(44.4)$ & 0.400 \\
Dyspnoea & $44(88.0)$ & $10(55.6)$ & 0.010 \\
Palpitation & $18(36.0)$ & $8(44.4)$ & 0.527 \\
Murmur & $8(16.0)$ & $2(11.1)$ & 0.909 \\
CHF & $46(92.0)$ & $4(22.2)$ & $<0.001$ \\
Atrial fibrillation & $0(0.0)$ & $4(22.2)$ & 0.004 \\
Mitral valve & $4(8.0)$ & $2(11.1)$ & 0.506 \\
obstruction & & & \\
\hline
\end{tabular}

*Figures in the parentheses denote corresponding percentage.

Data were analyzed using Chi-square (x2) Test.

Table-III

Association between neurological manifestations and type of tumour $(n=68)$.

\begin{tabular}{lccc}
\hline Neurologic & \multicolumn{2}{c}{ Atrial myxoma } & p value \\
\cline { 2 - 3 } manifestations & $\begin{array}{c}\text { Solid } \\
(\mathrm{n}=50)\end{array}$ & $\begin{array}{c}\text { Papillary } \\
(\mathrm{n}=18)\end{array}$ & \\
\hline Syncope & $0(0.0)$ & $16(88.9)$ & $<0.001$ \\
Dizziness & $0(0.0)$ & $6(33.3)$ & $<0.001$ \\
Speech disturbance & $0(0.0)$ & $2(11.1)$ & 0.017 \\
Hemiplegia & $0(0.0)$ & $10(55.6)$ & $<0.001$ \\
\hline
\end{tabular}

*Figures in the parentheses denote corresponding percentage.

Data were analyzed using Chi-square (x2) Test.

Table-IV

Association between embolic manifestations and type of tumor $(n=68)$.

\begin{tabular}{lccc}
\hline Embolic & \multicolumn{2}{c}{ Atrial myxoma } & p Value \\
\cline { 2 - 3 } manifestations & $\begin{array}{c}\text { Solid } \\
(\mathrm{n}=50)\end{array}$ & $\begin{array}{c}\text { Papillary } \\
(\mathrm{n}=18)\end{array}$ & \\
\hline Leg emboli & $0(0.0)$ & $8(44.4)$ & $<0.001$ \\
Cerebral emboli \# & $0(0.0)$ & $4(22.2)$ & 0.004 \\
\hline
\end{tabular}

*Figures in the parentheses denote corresponding percentage

I Data were analyzed using Chi-square (x2) Test; \#data were analyzed using Fisher's Exact Test.
Table-V

Comparison of histologic findings between types

of tumor $(n=68)$.

\begin{tabular}{lccc}
\hline Histologic & \multicolumn{2}{c}{ Atrial Myxoma } & p value \\
\cline { 2 - 3 } findings & $\begin{array}{c}\text { Solid } \\
(\mathrm{n}=50)\end{array}$ & $\begin{array}{c}\text { Papillary } \\
(\mathrm{n}=18)\end{array}$ & \\
\hline $\begin{array}{l}\text { Hemorrhage in } \\
\text { the stroma }\end{array}$ & $50(100.0)$ & $4(22.2)$ & $<0.001$ \\
Fibrosis \# & $42(84.0)$ & $0(0.0)$ & $<0.001$ \\
\hline
\end{tabular}

*Figures in the parentheses denote corresponding percentage

I Data were analyzed using Chi-square (x2) Test; \#data were analyzed using Fisher's Exact Test.

Table-VI

Association between embolic manifestations and type of tumor $(n=68)$.

\begin{tabular}{lccc}
\hline $\begin{array}{l}\text { Echocardiographic } \\
\text { findings }\end{array}$ & \multicolumn{2}{c}{ Atrial Myxoma } & $\mathrm{p}$ Value \\
\cline { 2 - 3 } Location of tumor & $\begin{array}{c}\text { Solid } \\
(\mathrm{n}=50)\end{array}$ & $\begin{array}{c}\text { Papillary } \\
(\mathrm{n}=18)\end{array}$ & \\
\hline Septum & $46(92.0)$ & $10(55.6)$ & 0.002 \\
Anterior left atrial wall & $2(4.0)$ & $0(0.0)$ & 0.538 \\
Lateral left atrial wall & $2(4.0)$ & $8(44.4)$ & $<0.001$ \\
Pedunculated stalk & $34(68.0)$ & $6(33.3)$ & 0.010 \\
\hline
\end{tabular}

*Figures in the parentheses denote corresponding percentage.

Data were analyzed using Chi-square (x2) Test;

\section{Discussion:}

There was no statistically significant difference of age distribution between two groups. Swartz et al has also shown the similar age incidence in his study but Shimono et al has higher age incidence. ${ }^{7,8}$ Male and female were found to be almost equally affected by both types of tumors $(p>0.05)$. Swartz et al has the similar sex incidence in their study like Shimono et al. ${ }^{7,8}$ The difference between the pre and post operative NYHA functional class distribution is statistically significant $(\mathrm{p}<0.05)$. All these data revealed not significant. The mean mitral valve gradient was $8.20 \pm 1.15 \mathrm{mmHg}$ for group A and 9.28+_2.04 mmHg for group B during preoperative period. During post operative period the mean mitral valve gradient was $5.13 \pm .67 \mathrm{mmHg}$ for group A and $6.04 \pm 1.45$ $\mathrm{mmHg}$ for group B. The aortic cross clamp time was $31.4 \pm 3.9$ minutes for group A and $32.5 \pm 4.2$ minutes for group B. The data showed the difference of mean aortic cross clamp time was 
insignificant ( $p>0.05$ ) between group A and group B. The data showed significantly higher post cross clamp time in group A than group B $(p<0.05)$. The extracorporeal circulation time required was $60.0 \pm 3.0$ minutes for group A and 79.0 \pm 6.0 minutes for group $B(p<0.05)$. The mean duration of ICU stay in hours in the group A was $36.9 \pm 3.4$ hours, significantly lower than the group B $48.0 \pm 3.6$ hours $(\mathrm{p}<0.05)$. The mean ventilation time (in hours) in

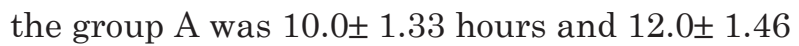
hours in group B $(p<0.05)$. Analysis indicate that no statistically significant difference were found between the groups $(p>0.05)$ by postoperative complication during in hospital follow up but one mortality in each group.

Neurological events and embolic manifestations were significantly more prevalent in group A (papillary tumor). Solid tumors showed more fibrosis and intra tumor hemorrhage. This solid nature makes these less likely to embolize. All 4 neurological features under study i.e. dizziness, syncope, speech disturbences and hemiplegia had significantly higher incidence in the papillary group which may be aributed to its potential for embolization. The incidence of peripheral and cerebral embolization was higher in group $\mathrm{A}$. Mr. Shimono \& Swartz have got the same features in their studies. ${ }^{7,8}$ The solid tumor has greater propensity for the attachment to septum than the soft tumor. For the extra-septum regions reverse is the true. The data showed no significant ( $p>0.05)$ difference of left atrial size (LA) between group A and group B. Dyspnea and CHF were significantly more prevalent in the solid tumor group, this is probably related to their obstructive potential to blood flow inside the heart. Among nonneurological features only Atrial Fibrillation was significantly more common in the papillary group.

To summarize the pedunculated solid tumors are more likely to arise from the septum and present with dyspnea and features of congestive cardiac failure. On the contrary papillary fragile tumors are more likely to arise from the septal free walls, embolize and present with embolic and neurogic clinical features.

\section{Conclusion:}

Our findings lend support to the view that different gross tumor types predict clinical presentation. Tumor location was also a good correlate of presenting symptoms. Further re-search must be done to delineate tumor morphology with clinical presentation.

\section{Conflict of Interest - None.}

\section{References :}

1. Kouchoukos NT, Blackstone EH, Doty DB, Hanley FL, Karp RB. Eds. Kirklin/ Barratt-Boyes: Cardiac Surgery. 3nd Edition. New York: Churchill Livingstone, 2003: 1639

2. Sharma G. Prisant ML. Atrial Myxoma. eMedicine, World medical Library; 2006:1-11

3. Pinede L, Duhaut P, Loire R. Clinical presentation of left atrial cardiac myxoma a series of 112 consecutive cases. Medicine 2001; 80: 159-172.

4. Zulkernine IM. Intracavitary cardiac tumours clinico pathological profile and surgical management' unpublished MS thesis, National Institute of Cardiovascular Diseases. Dhaka: University of Dhaka.1994.

5. Quashem MA. Large right atrial myxoma - an uncommon cardiac tumor needs urgent surgery. $J$ Bangladesh Coll Phys Surg 2008; 27: 52-55.

6. Aftabuddin M, Islam N, Alimuzzaman M. Acute myocardial infarction: A complication of left atrial myxoma. Indian J Chest Dis Allied Sci 1995; 37: 31.

7. Swartz MF, Lutz CJ, Chandan VS, Landas S, Fink GW. Atrial myxomas: Pathologic types, tumor location and presenting symptoms. J Cardiac Surg 2006; 21: 435-440.

8. Shimono T, Makino S, Kanamori Y. Left atrial myxo-mas: Using gross anatomic tumor types to determine clin-ical features and coronary angiographic findings. Chest 2006; 107: 674-679. 